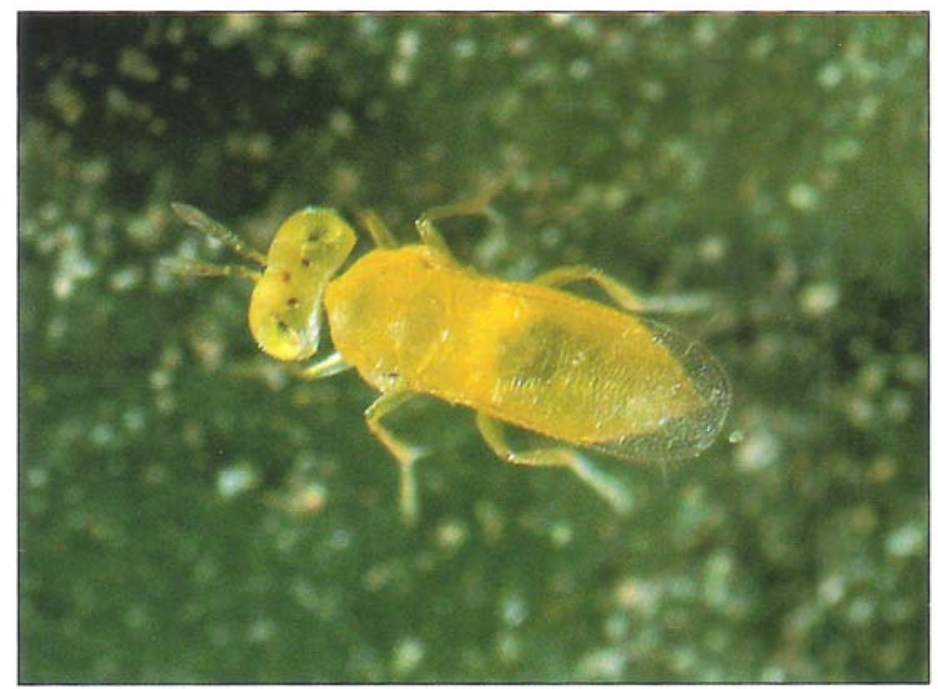

Resistance to Sevin may increase the effectiveness of the parasitic wasp, Aphytis melinus, in controlling California red scale in pesticidetreated orchards.

\title{
Laboratory-selected California red scale parasite is resistant to Sevin
}

\author{
Kevin M. Spollen $\square$ Marjorie A. Hoy
}

\section{A Sevin-resistant strain of the Cali- fornia red scale parasite, Aphytis melinus, is cross resistant to sev- eral citrus pesticides and is ready for implementation in citrus inte- grated pest management (IPM) systems.}

Often, natural enemies of insects are eliminated, along with the pests that are their meal tickets, when broad-spectrum pesticides are applied. Occasionally, however, natural enemies are found that resist pesticides and survive to prevent pest resurgences and secondary pest outbreaks. In California citrus, several broad-spectrum pesticides are applied to control citrus thrips, scale insects, and various mite and lepidopteran species. Application of these pesticides can reduce populations of Aphytis melinus, an effective parasite of the California red scale (CRS). Elimination of A. melinus after applications of broad-spectrum pesticides has been associated with secondary CRS outbreaks.

In a 1984 survey of pesticide tolerance in A. melinus throughout California, several field-collected colonies were laboratory-selected for pesticide resistance and by 1987, a Sevin-resistant (R) strain of the parasite had been developed. As reported in California Agriculture, January-February 1989), the R strain's resistance level increased fivefold over that of the unselected Base colony and was 20 times greater than the most susceptible (La Couague) colony. In addition, leaf bioassays in 1987 showed that the $R$ strain could survive better than the Base and La Couague colonies on citrus foliage with Sevin residues up to 75 days old.

Tolerance of the R strain to Sevin indicated that it could be utilized effectively in a citrus integrated pest management (IPM) program. However, up until 1987 research had focused on selecting $A$. melinus for resistance, and analysis of the $R$ strain was incomplete. Followup laboratory and field tests of the $R$ strain evaluated its potential for use in the field and for incorporation into mass-rearing programs by commercial insectaries.

\section{Tolerance to pesticides}

In pesticide residue tests with the Resistant (R) and the La Couague ( $\mathrm{S}$ ) colonies, a two-leaf bioassay was used to determine whether the $\mathrm{R}$ colony was more tolerant than the $S$ colony to residues of Supracide (methidathion), Lorsban (chlorpyrifos), Cygon (dimethoate), Carzol (formetanate), and Sevin (carbaryl). The two-leaf bioassay confined parasites between two treated leaves separated by a ring of plastic; the parasites spent most of their time on the treated leaves. The $S$ colony was considered representative of endemic orchard parasites in its tolerance to pesticides. Pesticides, such as Supracide and Lorsban, are applied to control scale, and Cygon and Carzol are applied to control citrus thrips in the San Joaquin Valley. If the Sevin-resistant strain also were tolerant of these pesticides, its efficacy within sprayed environments might be enhanced greatly.

Leaves were collected for the two-leaf bioassay from Eureka lemon trees sprayed with Sevin 80S, Sevin XLR, Lorsban 4E, Supracide 2E, Carzol 92SP, and Cygon 400 . Leaves were collected at 7-day intervals for the first 4 weeks and at 14-day intervals thereafter until 64 days postspray. Ten to 15 adult $A$. melinus from the $\mathrm{R}$ and $S$ colonies were introduced into each bioassay unit $(n=10)$ and were exposed to the residues for 24 hours.

The two Sevin formulations were tested to see whether one might be less toxic and thus preserve $A$. melinus for IPM. Because Sevin XLR is known to be less 
toxic to honeybees than the $80 S$ formulation, we wanted to determine if it also would be less toxic to $A$. melinus.

Of all pesticides tested, Sevin had the highest residual toxicity to the $S$ colony. The R colony survived significantly better than the $S$ colony on 1-, 8-, 15-, 22-, 29-, and 64-day-old residues of Sevin $80 S(\mathrm{P}<$ 0.05 ) (fig. 1). The R colony also survived significantly better than the S colony on 8-, 15-, 22-, 29-, and 43-day-old residues of Sevin XLR $(P<0.05)$. These results are consistent with previously published data that the $R$ strain survives better than susceptible colonies on Sevin-treated foliage.

Differences in toxicity of the XLR and $80 S$ formulations to the $R$ and $S$ colonies were minimal. With the $\mathrm{R}$ colony, 1-dayold XLR residues were more toxic than 1day-old $80 S$ residues, and with the $S$ colony 64-day-old 805 residues were more toxic than 64-day-old XLR residues. These differences were not found consistently throughout the 64-day test, however, and neither formulation could be recommended as a method to preserve either native or released $A$. melinus.

On Cygon and Supracide residues, the $R$ strain survived better than the S colony, but differences in survival were not as large as with the Sevin formulations. On Carzol residues, the $\mathrm{R}$ colony survived significantly better than the S colony on 8-, 15-, 22-, 29-, and 43-day-old residues ( $\mathrm{P} \leq$ 0.05 ). Carzol, a carbamate, is more closely related to Sevin than the other pesticides tested, which may explain the R strain's relatively high degree of tolerance.

The R colony was more susceptible than the $S$ colony to Lorsban, a result that disagrees with previous Lorsban leaf residue data. No explanation can be offered for this discrepancy. Results of plastic cup bioassays, in which parasites are exposed to dried pesticide residues, show that the $\mathrm{R}$ strain is more tolerant than the $\mathrm{S}$ colony on all of the pesticides tested, including Lorsban.

\section{Mode-of-inheritance tests}

Mode-of-inheritance tests were conducted using the $\mathrm{R}$ and an $\mathrm{S}$ (La Couague) colony to better understand the genetic basis of the Sevin resistance. Test results suggest that, once the $\mathrm{R}$ strain is released in the field and has mated with susceptible orchard parasites, resistance of their progeny will be intermediate between the pure $\mathrm{R}$ and $\mathrm{S}$ colonies. As far as field releases by commercial insectaries are concerned, however, females of the $\mathrm{R}$ strain will presumably have mated with resistant males before release.

If pesticides are applied before releasing the $R$ strain, native parasite populations may be substantially reduced so that progeny of released $R$ parasites will have a better chance of mating with each other upon emergence. We do not suggest that growers spray orchards for this purpose alone, but at certain times of the year sprays are necessary to control pests such as citrus thrips, scale insects, and various lepidopteran species. Because the R strain is tolerant to several citrus pesticides used to control these pests (Sevin, Supracide, Carzol, Cygon, Lorsban), applying any one of them may eliminate susceptible $A$. melinus and select for increased resistance in the released $R$ strain.

\section{Fitness and persisting resistance}

A relative fitness test was conducted with the $R$ and Base (S) colonies to determine whether selection for Sevin resistance in the $R$ strain had affected progeny production per female, progeny production per day, emergence rate of $\mathrm{F}_{1}$ adults, and sex ratio. Both $\mathrm{R}$ and $\mathrm{S}$ colonies had been reared in the laboratory for the same amount of time, and differences in the fitness parameters tested could be attributed to the presence or absence of resistance factors between the colonies. Results of these comparisons would be of particular concern to commercial insectaries interested in the reproductive capacities of the R strain.

A persistence-of-resistance test also was conducted to see whether the resistance level of the R strain would decline in the absence of selection with Sevin, and whether resistance in colonies of mixed $R$ and $S$ parasites would decline to levels of the pure $S$ colony. Test results could suggest what might happen to the resistance of the R strain over time if it were released in the field.

Results of the relative fitness test show that the mean number of progeny produced per female per day (over an 8-day egg-laying period) did not differ between the $R$ (2.56) and S (2.98) colonies, but the number of females produced per female was higher in the S colony (2.11) compared with the R colony (1.67). Insectary production of $R$ parasites, however, should not differ greatly from production

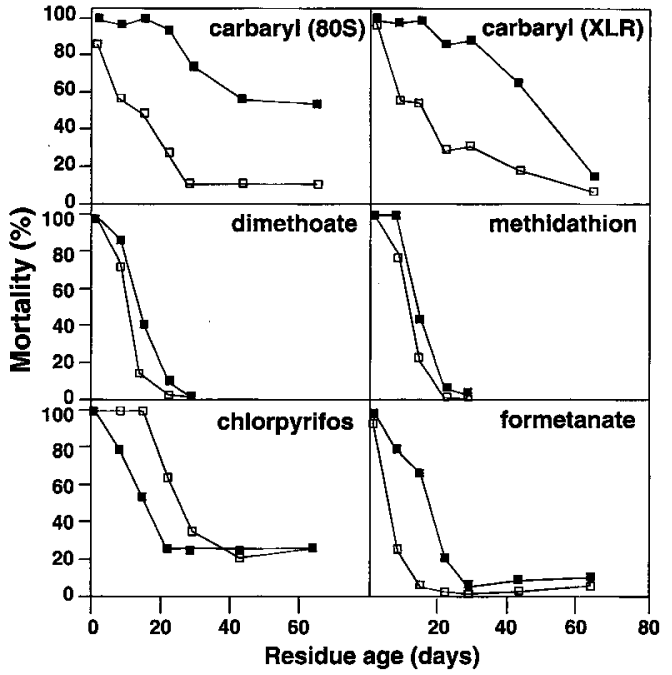

Fig. 1. Mortality of the La Couague (S, B) and Resistant $(R, \diamond)$ colonies of $A$. melinus on field-weathered residues of five citrus pesticides using a two-leaf bioassay with leaves collected from Santa Maria from June through August 1990. Control mortality did not exceed $5 \%$ for all test dates. Asterisks indicate significant differences $(\mathbf{P} \leq$ 0.05 ) between the $R$ and $S$ colonies on the same test date.

of $\mathrm{S}$ parasites. Parasite production in commercial insectaries is based on a 24-hour oviposition period by newly emerged $A$. melinus females. There were no significant differences between the $R$ and $S$ parents in the number of progeny produced on their first day of oviposition (table 1).

Emergence rate and mean developmental time of progeny were similar between the two colonies, indicating that selection for resistance had not altered the $R$ strain's developmental rate. The sex ratio was skewed more towards males in the $\mathrm{R}$ colony (table 1), but the R strain was $65 \%$ female, which is within the normal range for $A$. melinus ( 60 to $70 \%$ female).

In the persistence-of-resistance test, resistance in the $\mathrm{R}$ strain declined over 10 months (15 generations) after selection was discontinued, indicating that resistance was unstable. A mixture of $R$ and $S$

\begin{tabular}{|c|c|c|c|c|}
\hline \multicolumn{5}{|c|}{$\begin{array}{l}\text { TABLE 1. Progeny production and sex ratios of the Sevin-resistant }(R) \text { and } \\
\text { susceptible (S) colonies of } A \text {. melinus }\end{array}$} \\
\hline & $\begin{array}{l}\text { Total no. } \\
\text { progeny }\end{array}$ & $\begin{array}{c}\text { Mean no. } \\
\text { prog/" (day 1) } \\
(\mathrm{SE})^{\star} \dagger\end{array}$ & $\begin{array}{l}\text { Mean no. } \\
\text { "l" (day 1) } \\
\text { (SE) }\end{array}$ & Sex ratio \\
\hline Susceptible & 1,035 & $5.75 a(0.58)$ & $3.76 \mathrm{a}(0.32)$ & $2.64: 1 a$ \\
\hline Resistant & 936 & $5.09 a(0.56)$ & $3.19 a(0.35)$ & $1.96: 1 b$ \\
\hline
\end{tabular}

*(SE) $=$ standard error

†Values within columns followed by the same letter are not significantly different at the 0.05 level of significance. 
Fig. 2. Locations of orchards from which $A$. melinus populations were collected throughout California during 1990-91. Numbers in bold type inside the circle represent orSacramento
chards from which
Sevin-resistant
colonies were
collected. Sacramento
Sevin-resistant
colonies were
collected. Sacramento
Sevin-resistant
colonies were
collected.

(RS)

para-

sites initially showed an intermediate level of resistance between the pure $\mathrm{R}$ and $\mathrm{S}$ colonies; resistance declined slowly afterward for 10 months. An $R$ colony selected three times with Sevin during the 10 months showed no decline in resistance level. Selection of the RS colony after 8 months elevated its resistance level, indicating that RS hybrids in the field may respond to selection by insecticide applications.

Persistence-of-resistance test data suggest that the $R$ strain could maintain adequate levels of resistance for an entire citrus growing season (and for commercial insectary production). Reversion to susceptibility for the unselected R and RS strains occurred slowly during the 10month test in the laboratory. If resistance in the R colony declines in the field, application of Sevin or other pesticide may increase the level of resistance in the parasites.

\section{Sevin resistance in Aphytis}

In a release and recovery experiment with the $R$ strain during 1989 , two endemic field populations of $A$. melinus, collected from the San Joaquin Valley, showed evidence of Sevin resistance. A 1984 survey of pesticide tolerance in $A$. melinus showed no such tolerances to Sevin.

A survey of $11 \mathrm{~A}$. melinus populations collected from citrus orchards during 1990-91 supported 1989 data that field-developed resistance to Sevin has occurred in some San Joaquin Valley populations. Colonies were collected from the coastalintermediate region (colony 7 ), from the southern interior district (colonies 8 through 11), and from the San Joaquin Valley (colonies 1 through 6) (fig. 2).

Field-collected parasites were considered resistant if they showed 5\% survival or greater after being exposed to 33.6-ppm Sevin 805 using a plastic cup bioassay. Survival of the laboratory $R$ strain averages $22 \%$ at this concentration. Four colonies originating from Tulare County and collected in the San Joaquin Valley showed relatively high tolerances to Sevin. They were colonies 2 (9.5\% survival), 3 ( $12 \%$ survival), 4 ( $25 \%$ survival), and 5 ( $32.9 \%$ survival). Two susceptible colonies collected from the San Joaquin Valley were from Kern (no. 6) and Fresno (no. 1) counties. Colonies collected from Ventura (no. 7), San Bernadino (no. 8), and Riverside (nos. 9 through 11) counties showed no evidence of resistance (fig. 2).

\section{Commercial rearing}

Commercial insectaries are interested in obtaining pesticide-resistant colonies of $A$. melinus. Based on the 1990-91 survey, they may be inclined to collect wild populations of the parasite from the San Joaquin Valley. However, there is no information on the mode-of-inheritance or cross-resistance patterns in wild Aphytis populations, so the laboratory $R$ strain should remain of interest to commercial insectaries and citrus growers.

Although resistance in the $\mathrm{R}$ strain declines in the absence of selection, and its sex ratio and reproductive abilities have been somewhat affected through laboratory selection, it also is more tolerant of Supracide, Lorsban, Cygon, Carzol, and Sevin residues than are the laboratory $S$ colonies. If the $\mathrm{R}$ strain is released in pesticide-treated orchards, increased tolerance of the R strain to these pesticides may compensate for any disadvantages acquired by laboratory selection.

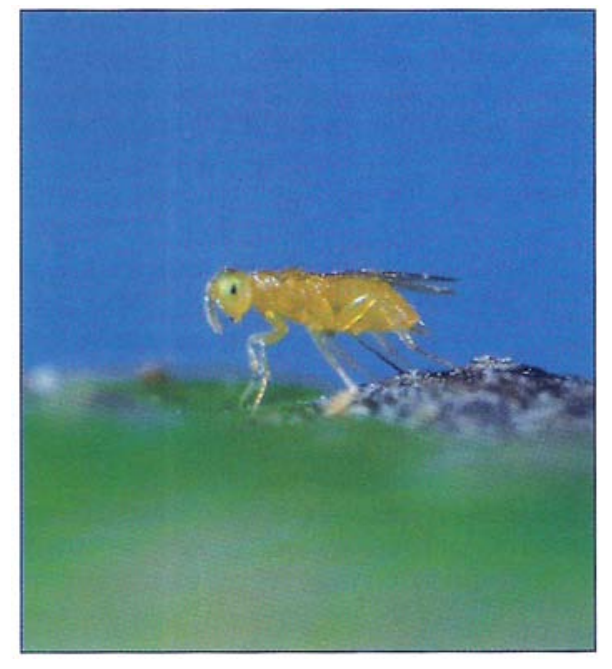

Aphytis melinus.
The R strain can easily be incorporated into the mass-rearing systems of commercial insectaries. However, special management strategies will be required. As described earlier, resistance in the $R$ strain declines slowly over 10 months (about 15 generations), if it is not periodically selected with Sevin. If the colony remains pure, resistance could be maintained throughout the majority of the release season. Insectaries should periodically select the $\mathrm{R}$ strain with Sevin to maintain resistance. One possible method for selection would be to spray the oleander scale-infested banana squash used to rear $A$. melinus with dilute solutions of Sevin. This method could continually select for resistance in adult parasites, as they encountered Sevin residues on the squash, and also could select for resistance in the immature stages of the parasite confined under the scale covering.

An alternative method for mass selecting parasites, effective on a small scale, would be to treat 1-gallon glass jars with dilute solutions of Sevin. Treating 1-pint jars with a Sevin $80 \mathrm{~S}$ solution $(0.0077 \mathrm{oz}$. [a.i.]/gal) will kill approximately $80 \%$ of the laboratory $R$ strain. This concentration is sufficient to maintain resistance in the $R$ strain, and will cause $100 \%$ mortality of susceptible parasites. The dilute Sevin solution is poured into and out of a jar. As the solution dries, it leaves a residue of Sevin on the inside of the jar. Food is provided for the parasites by streaking strips of plastic electrician's tape inside of the treated jar with undiluted honey. Holes are cut in the jar lids for ventilation and a piece of polyester gauze (also treated with Sevin) is placed over the top of the jar. The lid is screwed on the jar over the gauze, to secure the gauze. Parasites are introduced into the jar, which is held under constant light and temperature for 24 hours. Survivors of the selection are isolated on unparasitized oleander scale to continue colony production.

The best time for commercial insectaries to initiate a mass selection program, using treated jars, would be during November and December when demand for A. melinus is low. After selection, there would be ample time for parasite reproduction to reach optimum levels for spring releases. Selection could be done once or twice a year to maintain adequate levels of resistance.

Commercial insectaries often replace their previous colonies with field-collected parasites on a yearly basis, and this could pose a problem for maintaining the $R$ strain's purity if the field-collected parasites are susceptible to Sevin. Insectaries collect field colonies under the assumption that they will be better adapted to field conditions than their old colonies. There is 
no evidence, however, that this is true; theoretically, field-collected colonies could become laboratory adapted within their first few generations on oleander scale in the insectary. If commercial insectaries wish to maintain the R strain's purity, they should not add field-collected parasites to the $R$ colony, unless those parasites are resistant to Sevin (see below)

\section{Conclusions}

The laboratory-selected $\mathrm{R}$ strain of $A$. melinus is ready for practical use, and one commercial insectary has already received the strain for mass rearing and release. If adequate resistance can be maintained in the $R$ strain in an insectary throughout the spring and summer release periods, then orchards that receive the parasites may acquire a more permanent population of Sevin-resistant parasites. If resistant populations predominate in release areas, commercial insectaries could collect $A$. melinus from these areas to replenish their colonies yearly, and periodic selection of these parasites could maintain Sevin resistance in the insectary.

The R strain could provide better control of California red scale than susceptible parasites in pesticide-treated citrus orchards and could prevent pest resurgences or secondary pest outbreaks. The results: (1) fewer applications, or lower rates of application, of pesticides to control red scale; (2) lower control costs to growers, and (3) a reduced pesticide load in the environment.

Commercial insectaries and growers interested in obtaining the Sevin-resistant strain can contact Foothill Agricultural Research, $510^{1 / 2}$ West Chase Drive, Corona, CA 91720; phone: (714) 371-0120.

K. M. Spollen was a graduate student in the Department of Entomology, UC Berkeley, and is now an Assistant Entomologist, Department of Entomology, University of Hawaii, Honolulu; M. A. Hoy was a Professor, Department of Entomology, UC Berkeley, and is now a Professor, Department of Entomology and Nematology, University of Florida, Gainesville.

The authors thank K. Dunster (RhonePoulenc Agricultural Company), R. Hale (Hale Agricultural Services), J. Gordon (Pest Management Associates, Exeter, California) and Neil O'Connell (Farm Advisor, Tulare County) for coordinating field research and for technical assistance. Rhone-Poulenc, Dow Chemical, American Cyanamid, Nor-Am, and Ciba Geigy provided the pesticides. This research was supported in part by funds from Regional Research Project W-84, the Californio Agricultural Experiment Station, Citrus Research Board, UC Integrated Pest Management Project, and Rhone-Poulenc Company.

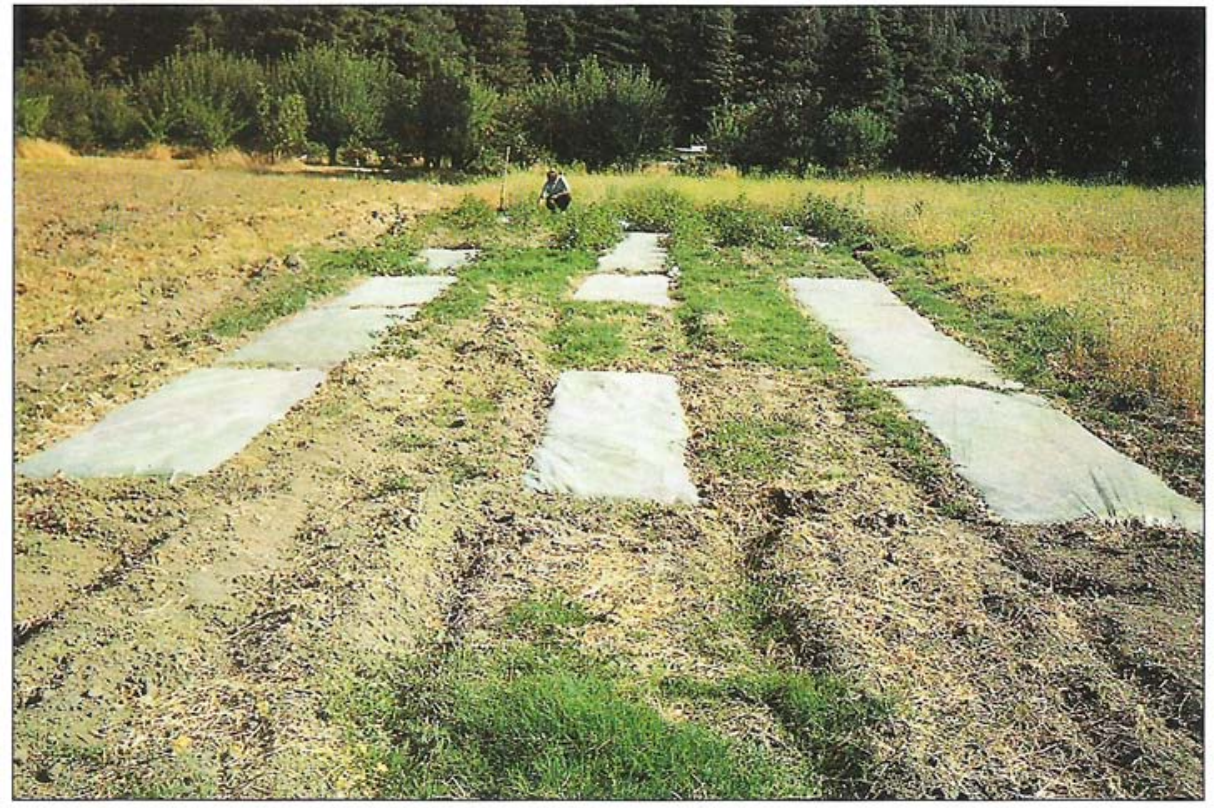

Site location for bermudagrass and redroot pigweed control in Humboldt County, 1989. The picture was taken 10 weeks after solarization began. The bare strips are where tarps were removed after 6 weeks; tarps still in place indicate the 14-week solarization.

\section{Perennial weeds respond to control by soil solarization}

\author{
Clyde L. Elmore $\square \quad J o h n$ A. Roncoroni $\square \quad$ Deborah D. Giraud
}

In soil solarization (soil tarping), solar energy is used to reduce soil pests. Clear polyethylene tarps may be used singly to cover pre-formed beds or they can be glued together to cover broad areas. Weed control is most effective when prepared beds are irrigated before being covered with polyethylene; however, when beds have drip lines, irrigation can take place after polyethylene is installed. Moisture under the tarp helps conduct heat and stimulates weed seeds to germinate; the heat then kills the seeds.

Winter annual species, such as annual bluegrass, common sowthistle, and shepherdspurse, are readily controlled by solarization; winter annual grasses are especially sensitive. Many summer annual species, including barnyardgrass and pigweed, are also controlled; the exception, sweet clover, is only partially controlled.

Perennial weeds are more difficult to control than annual weeds because their

\author{
Soil solarization in summers in \\ Central Valley and near-coastal \\ sites controlled bermudagrass and \\ johnsongrass covered by polyeth- \\ ylene tarps. Field bindweed was \\ also controlled during solarization, \\ but regrowth occurred. To maxi- \\ mize control and reduce the "edge" \\ effect - the regrowth of weeds at \\ the edges of fields when they are \\ not covered by tarps - the soil \\ must be completely covered with \\ intact polyethylene.
}

